\title{
Sorption models Of Cadmium (11) ion onto agricultural tuber wastes
}

\author{
Okoro I. A. and Abii T. \\ Department of Chemistry, Michael Okpara Univeristy \\ Agriculture Umudike, P.M.B 7267 Abia State Nigeria
}

\begin{abstract}
Sorption models and sorption capacities of tuber wastes for Cadmium (11) ion were investigated. The results showed that more than ninety-five per cent of initial concentration of Cadmium (11) ion in the aqueous solution was sorbed by each of these tuber wastes. The results obtained from the modelling of the results of sorption studies using Langmuir and Dubinin -Radushkevich models showed that the maximum sorption capacity (Qmax) obtained is thus yam peels> sweet potato peels $>$ cassava peels. The calculated porosity values (Qd) l/g showed yam peels $>$ sweet potato peels $>$ cassava peels. The calculated sorption energy $E$, showed the trend thus sweet potato peels > cassava peels > yam peels . The Langmuir constant obtained showed closely related values for the three tuber waste studied.
\end{abstract}

Keywords: Cadmium, sorption models, tuber waste biomass, biosorbent

\section{INTRODUCTION}

The current pattern of industrial development in most least developed countries (LDCs) of the world has changed the natural flow of materials thereby introduced new chemicals into the environment (Faisal and Hassamias (2004), lgwe et al., (2006). The rate at which effluents are discharged into the environment; water bodies land, have been on increase due to rapid growth of cities in the world. Almost all the industrial effluents contain Cadmium, lead, arsenic chromium, nickel, among other metals of industrial of interest Carson et al., (1986), Runnells et al., (1992).These metals when present in significant quantities in the environment causes health problems Beeman (1980). When these metal ions are present in sufficient amount in the environment they constitute source of pollution and pollutants. The sources of these environmental pollutants include; mining effluents refining and electroplating of metal wastes agricultural run off from farm land Okoro et al., (2007),Abia et al., (2005). These metal pollutants are conservative contaminants that are not easily bio gradable chemically, or biologically .They are therefore permanent chemical over load in the environment Elnady et al., (1996). The bioaccumulation of these metal pollutants have increased the interest of researchers in developing suitable remediation strategies Honma et al., (1978). Elaziz et al., (1991), MENCH (1994).The earliest remediation techniques include; precipitation, ion-exchange, lime softening reverse osmosis, coagulation and filtration .These early techniques are costly, not readily available and have complicated regeneration procedures not environmentally friendly Horsfall et al., (2004) , Baker et al., (1994), Lucido et al., (1991) Gang et al., (1998) , Gardean -Torresdey et al., (1996a), Gardean - Torresdey et al., (1996b).There is the need to develop a new cost effective alternative method which is the subject of this present study .In this study a report of the sorption models of tuber waste biomass for Cadmium (11) ion is thus presented. These tuber wastes include, yam peels (Dioscerea rotundata), cassava peels (Manhiot esculenta) and sweet potato peels (Ipomea batata).

Two isotherm equilibrium models were adapted and adopted in this study namely; Langmuir and Dubinin -Radushkevich models respectively.

Langmuir model: This is used to estimate the maximum sorption capacities of this tuber waste biomass denoted as Qmax corresponding to complete monolayer coverage on the biosorbent surface and is expressed as

$\mathrm{Qe}=\mathrm{Qmax} \cdot \mathrm{KICe} / 1+\mathrm{KICe}$

Where $\mathrm{KI}(\mathrm{I} / \mathrm{g})$ is a constant related to the sorption energy , Qmax is the maximum sorption upon complete saturation of the bomass surface, $\mathrm{Ce}$ is the initial concentration of Cadmium (11) ion in the aqueous solution $\mathrm{Qe}$ is the amount of Cadmium (11) ion sorbed by each of the tuber waste biomass at a 
specified time. A Linear rearrangement of equation 1 is given as

$$
\mathrm{Ce} / \mathrm{Qe}=1 / \mathrm{Qmax} \cdot \mathrm{KI}+\mathrm{Ce} / \mathrm{Qe}
$$

The experimental data from each of the tuber waste biomass sorption studies were fitted into equation 2 by plotting the values of $\mathrm{Ce} / \mathrm{Qe}$ against the values of $\mathrm{Ce}$. The slope of this plot gives the reciporal values for Qmax whereas the intercept of the plot yield the sorption energy value KI known as Langmuir constant $(12,2)$.

Dubinin-Radushkevich model: This is used to calculate the characteristic porosity of each these tuber waste biomass and the apparent energy $E$ of sorption. This model is represented as

$\mathrm{Qe}=\mathrm{Q}_{\mathrm{D}} \exp \left(-\mathrm{B}_{\mathrm{D}} \mathrm{RT} \ln (1+1 / \mathrm{Ce})\right)^{2}$

Where $Q e$ is the amount of Cadmium (11) ion sorbed by each of tuber waste biomass during the sorption studies, $Q_{D}$ is the Dubinin-Radushkevich constant which is the measure of the porosity value of each of the tuber wastes, $B_{D}$ is related to the energy of sorption per mole of Cadmium (11) ion is it moves from infinite distance to the biomass surface, $\mathrm{Ce}$ is the initial concentration of Cadmium (11) ion solution. A linear form of equation 3 is expressed as;

$\mathrm{LnQe} \quad=\ln Q_{D} \quad-2 B_{D} R T \ln (1+1 / \mathrm{Ce})$

The experimental data obtained from the sorption studies of Cadmium (11) ion onto each of the biomass were fitted into equation 4 by plotting values of $\quad$ InQe against the values of $R T \ln (1+1 / \mathrm{Ce})$. From the slope of the plot the apparent energy $E$ $2 \mathrm{~B}_{\mathrm{D}}$ for each of biomass was calculated thus,

$\mathrm{E}=1 / \sqrt{2} \mathrm{~B}_{\mathrm{D}}$

The intercept of the plot yield the porosity value $Q_{D}$. In this study a report of this modelling of Cadmium (11) ion values obtained from the sorption studies is presented.

\section{MATERIALS AND METHODS}

Sample collection: White yam (Dioscerea rotundata) tubers, cassava (Manhiot esculent) tubers and sweet potato (Ipomea batata) tubers were procured from the Root Crop Research Institute farm Umudike Abia State. These tuber crops were identified and authenticated by C.U. Osuagwu taxonomy, department of Botany Michael Okpara University of Agriculture Umudike Abia State Nigeria. All chemical reagents used are analytical grade from $\mathrm{BDH}$ chemicals Itd London.
Sample preparation: The tubers were washed clean and peeled manually with domestic knife. Each of the different tuber peels were collected into clean labelled stainless trays. The content(s) of each tray was Air -dried for 7 days. Each of these peels was further oven dried at $65{ }^{\circ} \mathrm{C}$ for $24 \mathrm{hrs}$. These dried tuber peels were each ground into powder using an electric milling machine (bin atone model). Each of these milled tuber wastes was sieved using a 2-mm steel sieve. The fine powder of each tuber peels was stored in a labelled plastic reagent bottle until it is required for the sorption studies.

Preparation of Cadmium (11) ion: Cadmium chloride equivalent to 18.3 gram Cadmium (11) ion was weighed out and taken into a one-litre volumetric flask, $25 \mathrm{ml}$ of distilled -deionised water was measured out and added into the flask shaken vigorously to achieve complete dissolution. The onelitre flask was made up to mark with distilled deionised water to yield one molar Cadmium (11) ion solution.

To study the effect of concentrations of Cadmium (11) ion on sorption behaviour of the three tuber wastes, a serial dilution was prepared. The serial dilution $\mathrm{s}$ was $0.1 \mathrm{M}, 0.2 \mathrm{M}, 0.4 \mathrm{M}$, and $0.6 \mathrm{M}$ of Cadmium (11) ion solution equivalent to $1,83 \mathrm{~g} / \mathrm{l}$. $3.66 \mathrm{~g} / \mathrm{l}, \quad 7.32 \mathrm{~g} / \mathrm{l}$, and $10.98 \mathrm{~g} / \mathrm{l} \mathrm{Cd}{ }^{2+}$ ion initial concentration respectively. Four conical flasks, each labelled with an appropriate concentration of Cadmium (11) ion were set up. Ten millilitre $(10 \mathrm{ml})$ of each of the concentrations was measured out and added into an appropriately labelled flask. Point one gram each of the powdered yam peels was added into each of the four flasks, stirred, allowed a contact time of 25- minutes. At the end of the 25-minutes intervals the content(s) of each flask was filtered using No40 what man filter paper assisted by suction pump into a clean reagent bottle properly labelled and the filter ate diluted with deionised water to $50 \mathrm{ml}$ mark and used for analysis. The above sorption study procedures described were exactly repeated using cassava peels and sweet potato peels as biosorbent materials respectively.

Atomic Absorption Spectrometric Analysis: Each of the three sample filtrates were analysed at $229 \mathrm{~nm}$ wavelength for Cadmium (11) ion using AAS spectrometer (unicam 969 model).The amount of Cadmium (11) ion sorbed by each of the tuber wastes was calculated by the difference. The percent sorbed amount of Cadmium (11) ion by each of these tuber wastes was calculated using the equation given as 
$\%$ sorption =Qe/Ce×100/1

Where symbols have the meaning as defined earlier in this work.

\section{RESULTS AND DISCUSSION}

The sorption of Cadmium (11) ion from aqueous solution by tuber waste biomass were studied and the data obtained thereof were modelled using standard isotherm equilibrium equations namely; Langmuir and Dubinin-Radushkevich models respectively The results obtained are presented in tables $(1,2)$ and figures 1,2 and 3.

Table 1: Values of sorption parameters obtained from tuber wastes

\begin{tabular}{|c|c|c|c|c|c|c|}
\hline Biomass & Ceg/l & Qeg/l & $\mathrm{Ce} / \mathrm{Qe}$ & $\operatorname{lnQe}$ & $R T \ln (1+1 / \mathrm{Ce})$ & \%Sorption \\
\hline Yam peels & 1.83 & 1.577 & 1.160 & 0.456 & 90.614 & 86.18 \\
\hline Yam peels & 3.66 & 3.581 & 1.023 & 1.276 & 50.217 & 97.84 \\
\hline Yam peels & 7.32 & 7.284 & 1.005 & 1.986 & 26.616 & 99.51 \\
\hline Yam peels & 10.98 & 10.948 & 1.003 & 2.393 & 18.117 & 99.71 \\
\hline Cassava peels & 1.83 & 1.798 & 1.0178 & 0.587 & 90.614 & 98.25 \\
\hline Cassava peels & 3.66 & 3.641 & 1.0108 & 1.287 & 50.217 & 98.93 \\
\hline Cassava peels & 7.32 & 7.295 & 1.0034 & 1.987 & 26.616 & 99.66 \\
\hline Cassava peels & 10.98 & 10.946 & 1.0031 & 2.393 & 18.117 & 99.69 \\
\hline Sweet potato peels & 1.83 & 1.751 & 1.045 & 0.560 & 90.614 & 95.68 \\
\hline Sweet potato peels & 3.66 & 3.551 & 1.037 & 1.267 & 50.217 & 97.02 \\
\hline Sweet potato peels & 7.32 & 7.24 & 1.0105 & 1.980 & 26.616 & 98.96 \\
\hline Sweet potato peels & 10.98 & 10.680 & 1.0281 & 2.368 & 18.117 & 97.27 \\
\hline
\end{tabular}

Table 2: Equilibrium constants obtained from the two isotherm models; Langmuir and Dubinin-Dushkevich models

\begin{tabular}{|l|l|l|l|l|l|}
\hline Biomass & Qmaxl/g & KIl/g & QDg/l & -B Calories/mole & E Calories \\
\hline Yam peels & 113.89 & 1.015 & 73.70 & 6.0 & 0.289 \\
\hline Cassava peels & 59.88 & 1.010 & 12.183 & 4.50 & 0.330 \\
\hline $\begin{array}{l}\text { Sweet potato } \\
\text { peels }\end{array}$ & 111.11 & 1.025 & 66.69 & 1.40 & 0.598 \\
\hline
\end{tabular}

Values are means of three determinations

From table 1 , it was observed that the three tuber waste biomass each sorbed more than ninety -five per cent of the initial concentration of the Cadmium (11) ion from the aqueous solution Figure 1, it showed the effect of increased concentration of Cadmium ion on sorptive capacities of these tuber waste biomass at constant biomass weight. It was observed that the yam peel and cassava peels do not attain saturation limit at the contact time of 25minutes used for the sorption studies, but the sweet potato peels as biosorbent did with the 25 -minutes time intervals used for this sorption studies. Figure 2 depicted the Langmuir isotherm models. From this plot the maximum sorption capacity of each of tuber waste biomass was calculation. From table 2 it was observed that yam peels has maximum sorption capacity of Qmax, $113.89 \mathrm{l} / \mathrm{g}$, followed by sweet potato peels with Qmax value of $111,11 \mathrm{l} / \mathrm{g}$. The cassava peels gave the least Qmax value. Figure 3 showed the Dubinin-Radushkevich model plot. It was from this plot that the porosity of each of these tuber wastes $Q_{D}$ value was determined. The sorption free 
Am. J. Sci. Ind. Res., 2011, 2(3): 381-385

energy $E$, value of each of these tuber wastes was also determined from figure 3 plot (table 2). It was observed from the table 2, that the sweet potato peels has the largest sorption free energy value of 0.598 calories per mole while the yam peels has the least $E$ value of 0.289 calories. Also from the table 2 the porosity values showed that the yam peels has the highest porosity value $Q_{D}$ of $73.7 \mathrm{~g} / \mathrm{l}$ whereas the cassava peels has the least porosity value $Q_{D}$ of $12,183 \mathrm{~g} / \mathrm{l}$.Both porosity value and the maximum sorption capacities of these tuber waste biomass modelled gave a positive correlation and can therefore be used to assess the efficiency and effectiveness of these tuber wastes for the removal of Cadmium (11) ion from aqueous solution. These two parameters can also be used in the assessment of other biomass like corn cobs, saw-dusts, rice -husks for their ability to remove Cadmium (11) ion from aqueous environments like industrial effluents waste water agricultural run -off waters among others.

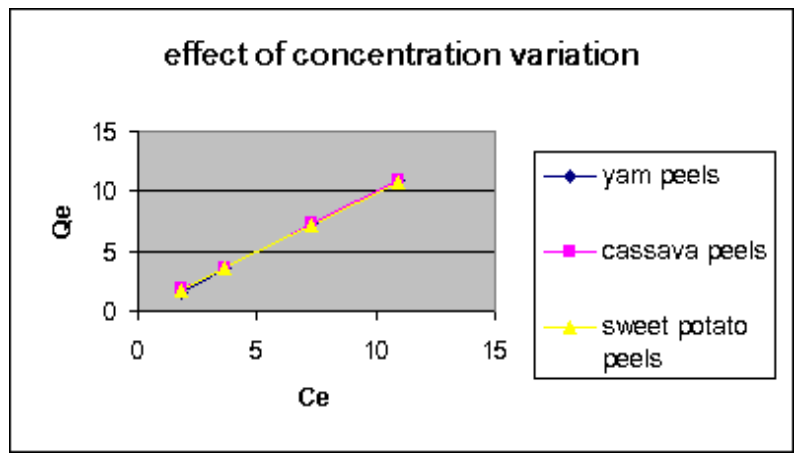

Fig 1: Effect of concentration variation

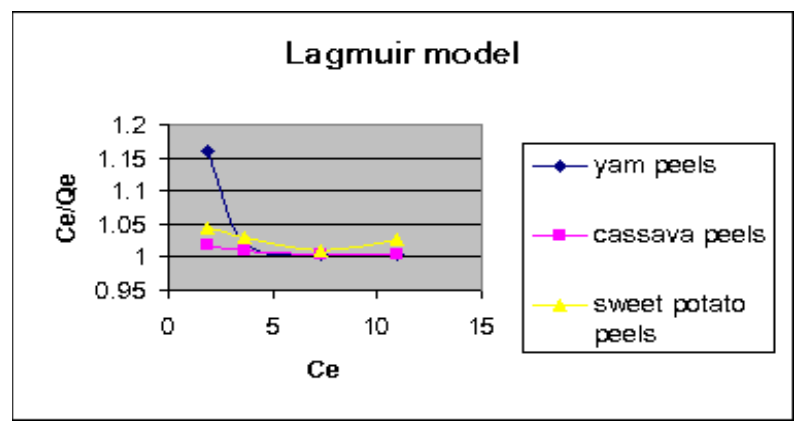

Fig 2: Langmuir model

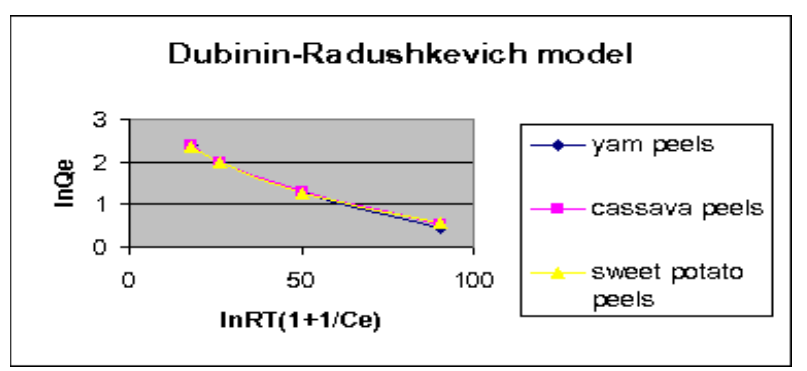

Fig 3: Dubinin-Radushkevich model

\section{REFERENCES}

1: Abia A, A and Igwe J.C (2005): Sorption kinetics and intraparticulate diffusivity of $\mathrm{Cd} \mathrm{Pb}$ and $\mathrm{Zn}$ on maize cobs.Afr.J.Biotechnology vol4 (6) 506-512.

2: Baker A.J.M, Reeves R.D and Hagar S A M (1994): Heavy metal accumulation and tolerance in British population of metllophytes, JandC press Itd new phytol 127 61-68.

3: Berman E,(1980): Toxic metal hazard and their analysis ,Heyden publishers Itd India. Pp48-101

4: Carson B, L Ellis H, V and McCann J, I (1986): Toxicology and biological monitoring of metal ion in human. Lewis publishers Chelsea Michigan USA pp65-297

5: El-aziz R Angle and Chaney B, I (1991): Metal tolerance of rhizobium metlotisolate from heavy metal contaminated soil. Soil boil.biochem. 23 795-807.

6: El-nady F E and Atta M, M (1996): Toxicity and bioaccumulation of metals in some marine biota from Egyptian coastal waters .J.Environ.Sci. Health. A-31 (7) 1529-1545.

7: Faisal M and Hassamias S (2004): Adsorption processes for water treatment .Butter wood publishers, Boston USA, pp106-113.

8: Gang $S$ and Weixing shi (1998): Sun flower as adsorbents for the removal of metal ions from waste water. Ind.Eng. chem... Res.37 1324-1328.

9: Gardean -Torresdey J.I and Salvador J, M (1996a): Copper adsorption by esterified and unesterified fraction of sphagnum peat moss and its different humic substances .J.Hazard Mater 48 191-206

10: Gardean -Torresedey J, I Tiemann K.J Gonzalez J,H Henning J.A and Tow sends M.S (1996b): Ability of silica immobilised medic ago sativa (alfa - alfa) to remove Cadmium, chromium, lead, and zinc ions from aqueous solution.J.Hazard Mater, 49 205-223.

11: Honma $F$ and Hirata $H$ (1978): A noticeable increase in $\mathrm{Cd}$ absorption by $\mathrm{Zn}$ deficient rice .Plant soil Sci plant nutria, $24295-297$.

12: Horsfall M and Spiff A, I (2004): Studies on the effect of $\mathrm{pH}$ on the sorption of $\mathrm{Pb}^{2+}$ and $\mathrm{Cd}^{2+}$ from aqueous 
Am. J. Sci. Ind. Res., 2011, 2(3): 381-385

solution by caladium bicolour (wild coco yam) biomass, Electronic J, Biotechnology (online) 15 December vol7 No $31-11$

13: Igwe J.C and Abia A.A (2006): A bio separation process for removing heavy metals from waste water using biosorbents. Afr.J Biotechnology vol5 (12) 11671179

14: Lucido S P and Iwakasi I (1991): The removal of $\mathrm{Cu}^{2+}$ from the mine effluents using fresh water green algae (cyanidium caldarium). Proceeding of the symposium on the environmental management for 1990s. Denver, Colorado USA February 25-28, 142 143.
15: Mench M.J (1994): A mimicked in situ remediation study of metal contaminated soil with on emphasis on Cadmium, and lead. Journal of environ.qual. 23 58-65

16: Okoro I.A and Ejike E, N (2007): Sorption models of lead (11) ion removal from aqueous solution using common edible fruit wastes. European journal of scientific research vol17 N02 270-276

17: Runnells D.D and Shepard T.A (1992): Metal in water, determining natural background concentration in mineralised area .Environ.Sci. Techno. 26 2316-2323 